\title{
Identification of Ascitic Fluid Bacterial Pathogens in Spontaneous Bacterial Peritonitis in Nile Delta and Its Impact on Clinical Outcome of these Patients
}

\author{
Haidy S. Khalil ${ }^{1^{\star}}$, Walaa Elkhalawany ${ }^{2}$, Mohamed Elhendawy ${ }^{2}$, Rehab Badawi ${ }^{2}$ \\ Marwa Ahmed Abdelwahab ${ }^{3}$ and Sherief Abd-Elsalam ${ }^{2}$ \\ ${ }^{1}$ Department of Microbiology and Immunology, Faculty of Medicine, Helwan University, Egypt. \\ ${ }^{2}$ Department of Tropical Medicine and Infectious Diseases, Faculty of Medicine, Tanta University, \\ Egypt. \\ ${ }^{3}$ Department of Microbiology and Immunology, Faculty of Medicine, Tanta University, Egypt.
}

Authors' contributions

This work was carried out in collaboration between all authors. Author SAE designed the study, performed the statistical analysis, wrote the protocol and wrote the first draft of the manuscript. Author HSK managed literature searches and reviewed the manuscript. Authors HSK and MAA managed the practical work of the study. All authors collaborate in the analyses of the study and literature searches. All authors read and approved the final manuscript.

\author{
Article Information \\ DOI: $10.9734 / B M R J / 2016 / 29869$ \\ Editor(s): \\ (1) Ng Zhi Xiang, Department of Biomedical Sciences, Faculty of Medicine, MAHSA University, Malaysia. \\ (1) Einar Arnbjornsson, Skåne University Hospital and Lund University, Lund, Sweden. \\ (2) Wagih Mommtaz Ghannam, Mansoura university, Egypt. \\ Complete Peer review History: http://www.sciencedomain.org/review-history/16688
}

Original Research Article

Received $1^{\text {st }}$ October 2016 Accepted $19^{\text {th }}$ October 2016 Published $27^{\text {th }}$ October 2016

\begin{abstract}
Aims: This study aimed to identify ascetic fluid bacterial pathogens and their antibiotic resistance profile in Spontaneous Bacterial Peritonitis (SBP) patients in Nile delta and its impact on the clinical outcome of these patients.

Study Design: Retrospective observational study.

Place and Duration of Study: Patients enrolled in this study were admitted to Tropical Medicine and Infectious Diseases Department, Faculty of Medicine, Tanta University, Egypt. Further laboratory work was carried out at Microbiology and Immunology Department, Faculty of Medicine, Tanta University, Egypt, from July 2015 to June 2016.

Methodology: 247 patients with liver cirrhosis and ascites who met the clinical criteria for
\end{abstract}


suspicion of SBP including: fever, encephalopathy, refractory ascites and abdominal pain were enrolled in the study. Patients were subjected to thorough history and clinical examination. Ascetic fluid sampling was done for every patient and ascetic fluid analysis was done including cell counts and differential counts. Also, ascitic fluid culture, microbiological testing and antimicrobial sensitivity tests were done.

Results: Out of 247 patients enrolled in this study with liver cirrhosis, ascites and clinical suspicion of SBP, 138 patients were excluded. These excluded patients included: 91 patients had ascetic fluid neutrophils below 250 cells $/ \mathrm{mm} 3,4$ patients were cases of secondary peritonitis with polymicrobial culture and 43 patients were found to started empirical antibiotics within 5 days of admission. Out of 109 patients who had SBP, 28 only were culture positive. Among culture positive SBP, $16(57.1 \%)$ were Gram positive and 12 (42.9\%) were Gram negative. The most common organism isolated was Gram positive Enterococci followed by E. coli and Staph aureus.

Conclusion: While Gram negative bacteria were the main infectious agents causing SBP a few decades ago, and are still reported to be so in the most recent recommendations and reviews, Gram positive bacteria are now predominant and there is a rising prevalence of bacteria with reduced susceptibility to cephalosporins and fluoroquinolones as regarding this study only and not including previous data or speculations. Current international guidelines recommend the use of a third-generation cephalosporin for empirical treatment of SBP which raise the questions about these guidelines and if they are still valid.

Keywords: Spontaneous bacterial peritonitis; gram positive bacteria; gram negative bacteria; third generation cephalosporins; bacterial resistance.

\section{INTRODUCTION}

Spontaneous bacterial peritonitis (SBP), defined as an infection of ascites in the absence of a contiguous source of infection [1]. SBP is a common and potentially fatal bacterial infection in patients with decompensated cirrhosis and ascites $[2,3]$. The short term mortality may reach up to $40 \%$ mainly due to sepsis, hepatorenal syndrome, and liver failure [4].

Translocation of bacteria from I ntestine into the ascitic fluid in SBP occurres secondary to impaired humoral and cellular immune responses $[5,6]$. SBP is also associated with a poor prognosis for patients, with high mortality rates reaching up to $70 \%$ at 1 year [3].

Early diagnosis and early optimal treatment of these infections with appropriate antibiotics and the prevention of hepatorenal syndrome with albumin are required [7].

Current European and most other international guidelines recommend the use of a thirdgeneration cephalosporin as the first choice, or amoxicillin-clavulanate acid or fluoroquinolones as an alternative choice $[5,8]$. However, these recommendations are based mainly on clinical trials that were very often conducted a decade or more ago, and on the assumption that $E$. coli would be involved in nearly half of the cases [9].

Several studies have pointed out marked changes in the causative bacteria of SBP and extreme changes in antibiotic resistance profiles. In particular, the potential emergence of Enterococci, methicillin-resistant $S$. aureus (MRSA), or fluoroquinolone-resistant bacteria, following norfloxacin prophylaxis, is also a cause of concern since they may be associated with a higher risk of therapeutic failure [10].

The antibiotic resistance rate especially for thirdgeneration cephalosporins (including cefotaxime and ceftazidime), ciprofloxacin, and ofloxacin are increasing dramatically. Failure of first-line empirical therapy for SBP is associated with poor survival and increased mortality, therefore, early identification of patients with SBP due to cefotaxime or other third generation cephalosporins resistant bacteria is crucial $[10,11]$.

So, the aim of the study was to identify ascitic fluid bacterial pathogens in Spontaneous Bacterial Peritonitis in Nile delta and its impact on clinical outcome of these patients.

\section{PATIENTS, MATERIALS AND METHODS}

The patients in the present study were enrolled from Tanta University, Tropical medicine department. A written consent was taken from all participants in this research and the study was approved by the local Ethical Committee.

The study included patients with Liver cirrhosis with ascites and proved to have SBP with ascitic 
fluid $P M N L \geq 250$ cells $/ \mathrm{mm}^{3}$ while those with ascetic fluid $\mathrm{PMNL}<250$ cells $/ \mathrm{mm}^{3}$ were excluded from the study. Patients with ascitic fluid culture showing polymicrobial infections were also excluded from the study. Moreover, patients who started empirical antibiotics without prior culture were excluded from the study.

Ascitic fluid sampling was done for every patient by the standard diagnostic paracentesis method, and ascitic fluid analysis was done including cell counts and differential counts. Also, ascitic fluid culture and microbiological testing were done. Peritoneal fluid sampling was performed under complete aseptic precautions to ensure the sterility of the samples. Culture-positive SBP was diagnosed in the presence of ascitic fluid PMNL $\geq 250$ cells $/ \mathrm{mm} 3$ and positive ascitic fluid culture for a single organism. Culture-negative neutrocytic ascites was diagnosed when the ascitic fluid culture results are negative, but the PMNL counts are 250 cells $/ \mathrm{mm} 3$ or higher. A code number for each patient was used, symbols to the name and address were kept in a special file. Patients' names were hidden during the research work.

\section{RESULTS}

The study enrolled 247 patients with liver cirrhosis, ascites and clinical suspicion of SBP. Ninety one patients had ascetic fluid neutrophils below 250 cells $/ \mathrm{mm} 3$. Four patients were cases of secondary peritonitis with polymicrobial culture. Forty three patients were found to started empirical antibiotics within 5 days of admission. So, they were excluded from the study (Fig. 1).

The microbiological spectrum found in our patients was $57.1 \%$ (16/28) Gram-positive organisms while $42.9 \%$ (12/28) were Gramnegative organisms. Amongst the Gram positive cocci, Enterococcus bacteria $(56.2 \%)$ was the commonest followed by $S$. aureus $(43.8 \%)$. E. coli $(58.3 \%)$ was the commonest bacteria amongst the Gram negative bacilli followed by Enterobaceria (25\%), Pseudomonas spp. (8.3\%) and Klebsiella spp. (8.3\%) (Table 1).

In our study, (54.7\%) of the isolated bacteria were third-generation cephalosporin-resistant. Resistance to quinolones was observed in (58.9\%) microorganisms. Amoxycillineclavulanate resistance was demonstrated in (53.6\%). The least resistance was observed to gentamicin (17.9) and impenem (7.14\%) (Table 2).
Table 1. Bacteria isolated from ascitic fluid in culture positive SBP

\begin{tabular}{lll}
\hline Type of bacteria & Number & $\%$ \\
\hline Gram-negative bacteria & 12 & $42.9 \%$ \\
Escherichia coli & 7 & $58.3 \%$ \\
Klebsiella spp. & 1 & $8.3 \%$ \\
Pseudomonas spp. & 1 & $8.3 \%$ \\
Enterobacter spp. & 3 & $25 \%$ \\
Gram-positive bacteria & 16 & $57.1 \%$ \\
Enterococcus spp. & 9 & $56.2 \%$ \\
Staphylococcus aureus & 7 & $43.8 \%$ \\
\hline
\end{tabular}

Table 2. Patterns of antibiotic resistance among all positive cultures

\begin{tabular}{ll}
\hline Antibiotic & Resistance rate \\
\hline Ampicillin & $78.6 \%$ \\
Amoxicillin & $75 \%$ \\
Ampicillin-sulbactam & $53.6 \%$ \\
Cefotaxime & $60.7 \%$ \\
Ceftriaxone & $57.1 \%$ \\
Ceftazidime & $46.4 \%$ \\
Ciprofloxacin & $64.3 \%$ \\
Ofloxacin & $53.6 \%$ \\
Gentamicin & $17.9 \%$ \\
Impenem & $7.14 \%$ \\
\hline
\end{tabular}

\section{DISCUSSION}

Cirrhotic patient with ascites are particularly susceptible to spontaneous bacterial peritonitis due to altered gut permeability, suppression of the reticuloendothelial system and bacterial overgrowth [5]. Gram-negative bacteria (most frequently $E$. coli) through translocation from the intestinal lumen are responsible for the majority of SBP cases [12].

However, the preponderance of infections caused by Gram-negative bacteria due to epidemiological changes has shifted to a higher prevalence of infections being caused by Grampositive cocci. This may be explained by increasing antibiotic prophylaxis, exposure to hospital environment, and frequent invasive procedures [13].

In our study which was done on 247 patients presented with symptoms such as low grade fever, rapidly accumulating ascites, unexplained deterioration of general condition and some of them had abdominal pain. They were admitted to the hospital suspected of having SBP and diagnostic paracentesis was done for all patients. PMN was found $<250$ cells $/ \mathrm{mm}^{3}$ in 138 patients and 250 cells $/ \mathrm{mm}^{3}$ in 109 patients. Ascitic fluid cultures among those 109 patients were found negative in 
$81(74.3 \%)$ patient and positive only in 28 $(25.6 \%)$ patients.

The rate of culture-positive cases was obviously low in our study despite the fact that ascitic fluid cultures were performed by the standard (culture-bottle) method. On the other hand, previous studies reported the culture-positive rate of SBP ascites to be ranging about $40 \%$ of cases of SBP [14], and Bibi et al. [15] reported the culture-positive rate of SBP ascites to be about $50 \%$ [15]. However, similar results to our study were reported with lower rate of culturepositive rate of SBP in about $39 \%$ of cases and they suggested that the low rate probably depended on an earlier diagnosis of the infection [16]. Sajjad M et al. [17] has reported much lower rates of culture positivity to even below $25 \%$. This difference could be attributed due to the different culture techniques [17].

The microbiological spectrum found in our patients was $57.1 \%$ (16/28) Gram-positive organisms while $42.9 \%$ (12/28) were Gram- negative organisms. Amongst the Gram positive cocci, Enterococcus spp. bacteria (56.2\%) was the commonest followed by S. aureus (43.8\%). E. coli $(58.3 \%)$ was the commonest bacteria amongst the Gram negative bacilli followed by Enterobacer spp. (25\%), Pseudomonas spp (8.3\%) and Klebsiella spp. (8.3\%).

Our findings are in agreement with several reports that showed a higher frequency of Grampositive bacterial infections associated with SBP $[18,19]$. Gou et al. [20] report also supported the view that Gram-positive pathogens were predominant among ascites fluid samples from SBP patients [20]. Our results were partial agreement with Hardick et al. [21] who found even much higher frequency of Gram positive bacteria; as $83.3 \%(10 / 12)$ were diagnosed as gram -positive organisms by Broad-Range PCR [21]. Our results were also in accordance with Alexopoulou et al. [13], who isolated the majority of pathogens from patients with SBP were grampositive cocci (55\%) [22].

\section{Enrolled $(n=247)$}

Liver cirrhosis, Ascites, Clinical suspicion of SBP.

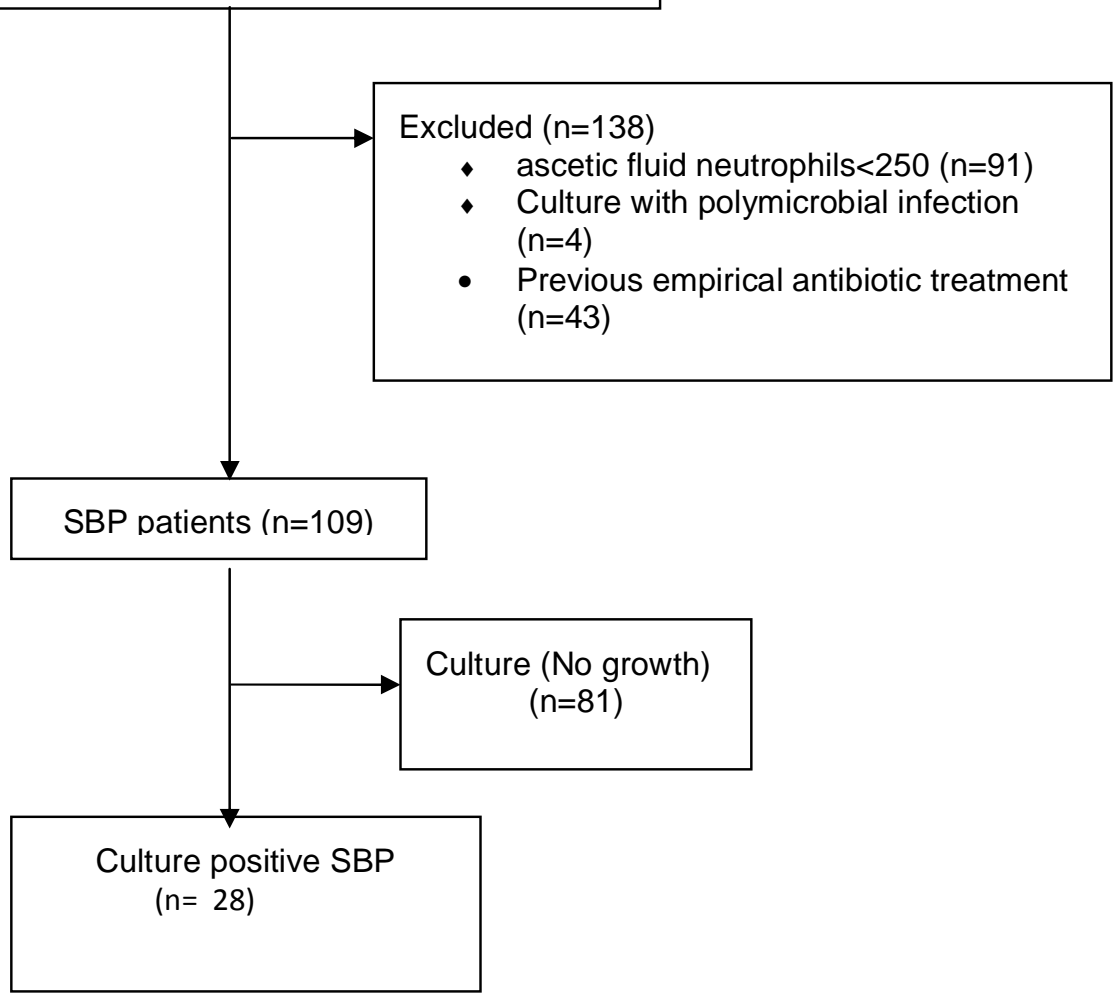

Fig. 1. Flow diagram of Identification of ascitic fluid bacterial pathogens in spontaneous bacterial peritonitis in Nile Delta 
In contaray, lqbal et al. [23] reported from Khyber Teaching Hospital, Peshawar that Gram negative bacteria was predominant with $E$. coli were $58.13 \%$ in SBP ascites followed by Streptococcus pneumoniae in $18.60 \%$, S. aureus in $9.13 \%$ and Acinetobacter in $4.63 \%$ cases [23]. Also, Haider et al. [24] found $60 \%$ of the cultured bacteria as Gram negative bacilli and $24 \%$ as Gram positive cocci, amongst these E. coli were $30 \%$, Klebsiella spp. 14\% and Enterobacter spp. and Pseudomonas spp 4\% each [24].

The development of new antibiotics and the possibility of an earlier diagnosis of SBP have dramatically changed the natural history of resolution from $25 \%$ before 1980 to $70 \%-90 \%$ in the last few years [25]. The administration of an inappropriate therapy is associated to an increased mortality. The choice of the empirical therapy should be based not only on the severity and the origin of the infection, but also on the local microbiological profile [5].

In our study, (54.7\%) of the isolated bacteria were third-generation cephalosporin-resistant. Resistance to quinolones was observed in (58.9\%) microorganisms. Amoxycillineclavulanate resistance was demonstrated in (53.6\%). The least resistance was observed to gentamicin (17.9) and impenem (7.14\%).

As third-generation cephalosporins were the first choice empirical antibiotics against SBP and other infections. The bacterial resistance to these antibiotics was evaluated and $36.2 \%$ to $50 \%$ of isolates from cirrhotic patients were resistant [26].

A position statement based on the EASL Special Conference 2013 recommended as empirical treatment for community acquired infections either cefotaxime (or ceftriaxone) or amoxicillin/ clavulanate and for nosocomial either piperacillin/ tazobactam or meropenem \pm glycopeptides [27].

\section{CONCLUSION}

While Gram negative bacteria were the main infectious agents causing SBP a few decades ago, and are still reported to be so in the most recent recommendations and reviews. Gram positive cocci are now predominant and there is rising prevalence of bacteria with reduced susceptibility to cephalosporins and fluoroquinolones as regarding this study only and not including previous data or speculations.
Current international guidelines recommend the use of a third-generation cephalosporin for empirical treatment of SBP which raise the questions about these guidelines and if they are still valid.

\section{COMPETING INTERESTS}

Authors have declared that no competing interests exist.

\section{REFERENCES}

1. Tandon P, Garcia-Tsao G. Bacterial infections, sepsis, and multiorgan failure in cirrhosis. Semin Liver Dis. 2008;28:26-42.

2. Appenrodt B, Lehmann LE, Thyssen L, Gentemann M, Rabe C, Molitor E, et al. Is detection of bacterial DNA in ascitic fluid of clinical relevance? Eur J Gastroenterol Hepatol. 2010;22:1487-94.

3. Barreales M, Fernandez I. Spontaneous bacterial peritonitis. Rev Esp Enferm Dig. 2011;103:255-63.

4. Elfert A, Abo Ali L, Soliman S, Ibrahim S, Abd-Elsalam S. Randomized-controlled trial of rifaximin versus norfloxacin for secondary prophylaxis of spontaneous bacterial peritonitis. Eur J Gastroenterol Hepatol; 2016. (In press).

5. Fagan KJ, Rogers GB, Melino M, Arthur $\mathrm{DM}$, Costello ME, Morrison $\mathrm{M}$, et al. Ascites bacterial burden and immune cell profile are associated with poor clinical outcomes in the absence of overt infection. Plos One. 2015;10(3):e0120642.

6. Soriano G, Esparcia O, Montemayor M, Guarner-Argente C, Pericas R, Torras X, et al. Bacterial DNA in the diagnosis of spontaneous bacterial peritonitis. Aliment Pharmacol Ther. 2011;33:275-84.

7. Sort $P$, Navasa M, Arroyo V, VAldeguer X, Planas R, Ruiz-del-Arbol L, et al. Effect of intravenous albumin on renal impairment and mortality in patients with cirrhosis and spontaneous bacterial peritonitis. $\mathrm{N}$ Engl J Med. 1999;341(6):403-9.

8. Wiest R, Krag A, Gerbes A. Spontaneous bacterial peritonitis: Recent guidelines and beyond. Gut. 2012;61:297-310.

9. Abd-Elsalam S, Soliman H, Elkhalawany W, Haidy Khalil, Samah Soliman, Eslam Ismail, et al. Is spontaneous bacterial peritonitis still responding to third generation cephalosporins?: A single centre experience. Int J Curr Microbiol App Sci. 2016;5(5):392-9. 
10. Fernandez J, Acevedo J, Castro M, Garcia O, de Lope CR, Roca D, et al. Prevalence and risk factors of infections by multiresistant bacteria in cirrhosis: A prospective study. Hepatology. 2012;55: 1551-61.

11. Sheikhbahaei S, Abdollahi A, Hafezi-Nejad $\mathrm{N}$, Zare E. Patterns of antimicrobial resistance in the causative organisms of spontaneous bacterial peritonitis. Int $\mathrm{J}$ Hepatol. 2014;2014: 917856.

12. Guarner C, Soriano G. Spontaneous bacterial peritonitis. Semin Liver Dis. 1997; 17:203-17.

13. Alexopoulou A, Papadopoulos $\mathrm{N}$, Eliopoulos DG, Alexaki A, Tsiriga A, Toutouza $M$, et al. Increasing frequency of gram-positive cocci and gram-negative multidrug-resistant bacteria in spontaneous bacterial peritonitis. Liver Int. 2013;33:975-81.

14. Lutz P, Nischalke HD, Strassburg CP, Spengler U. Spontaneous bacterial peritonitis: The clinical challenge of a leaky gut and a cirrhotic liver. World J Hepatol. 2015;27;7(3):304-14.

15. Bibi S, Ahmed W, Arif A, Khan F, Alam SE. Clinical, laboratory and bacterial profile of spontaneous bacterial peritonitis in chronic liver disease patients. J Coll Physicians Surg Pak. 2015;25:95-9.

16. European Association for the Study of the Liver. EASL clinical practice guidelines on the management of ascites, spontaneous bacterial peritonitis, and hepatorenal syndrome in cirrhosis. J Hepatol. 2010;53: 397-417.

17. Sajjad M, Khan ZA, Khan MS. Ascitic Fluid culture in cirrhotic patients with spontaneous bacterial peritonitis. J Coll Physicians Surg Pak. 2016;26:658-61.

18. Cholongitas E, Papatheodoridis GV, Lahanas A, Xanthaki A, KontouKastellanou C, Archimandritis AJ. Increasing frequency of Gram-positive bacteria in spontaneous bacterial peritonitis. Liver Int. 2005;25:57-61.
19. Fernandez J, Acevedo J, Castro M, Garcia O, de Lope CR, Roca D, et al. Prevalence and risk factors of infections by multiresistant bacteria in cirrhosis: A prospective study. Hepatology. 2012; 55:1551-61.

20. Gou Y, Zhang F, Liang Z, Bai X, Pan L, Wang $W$, et al. Pathogens change in spontaneous bacterial peritonitis patients with cirrhosis. African $\mathrm{J}$ Microbiol Res. $2011 ; 5(1): 1-7$.

21. Hardick J, Won $H$, Jeng $K$, Hsieh $Y H$, Gaydos CA, Rothman RE, et al. Identification of bacterial pathogens in ascitic fluids from patients with suspected spontaneous bacterial peritonitis by use of broad-range PCR (16S PCR) coupled with high-resolution melt analysis. $\mathrm{J}$ Clin Microbiol. 2012;50(7):2428-32.

22. Alexopoulou A, Vasilieva L, Agiasotelli D, Siranidi K, Pouriki S, Tsiriga A, et al. Extensively drug-resistant bacteria are an independent predictive factor of mortality in 130 patients with spontaneous bacterial peritonitis or spontaneous bacteremia. World J Gastroenterol. 2016;22(15):404956

23. Iqbal S, Imran N, Alam N, et al. Incidence of spontaneous bacterial peritonitis in liver cirrhosis, the causative organisms and antibiotic sensitivity. JPMI. 2004;18:614-9.

24. Haider I, Ahmad I, Rashid A, Bashir H. Causative organisms and their drug sensitivity pattern in ascetic fluid of cirrhotic patients with spontaneous bacterial peritonitis. JPMI. 2008;22:333-9.

25. Navasa M, Fernández J, Rodés J, et al. Bacterial infections in liver cirrhosis. Ital $\mathrm{J}$ Gastroenterol Hepatol. 1999;31:616-25.

26. Runyon BA. AASLD Practice Guidelines Committee. Management of adult patients with ascites due to cirrhosis: an update. Hepatology. 2009;49:2087-107.

27. Jalan R, Fernández J, Wiest R, Schnabl B, Moreau R, Angeli P, et al. Bacterial infections in cirrhosis: A position statement based on the EASL Special Conference 2013. J Hepatol. 2014;60:1310-24.

(c) 2016 Khalil et al.; This is an Open Access article distributed under the terms of the Creative Commons Attribution License (http://creativecommons.org/licenses/by/4.0), which permits unrestricted use, distribution, and reproduction in any medium, provided the original work is properly cited.

Peer-review history:

The peer review history for this paper can be accessed here: http://sciencedomain.org/review-history/16688 